\title{
The Spirit of Zhuangzi and Chinese Utopian Imagination
}

\author{
LIU Jianmei \\ Hong Kong University of Science and Technology, Hong Kong, China
}

\begin{abstract}
Through examining Zhou Zuoren's ideal of new village and Lin Yutang's novel Unexpected Island, this article analyzes modern Chinese utopian imaginations inspired by Zhuangzi’s spirit, which complements what has been lacking in the modern utopian dream—individual spiritual liberation that resists any despotism of humanity and a more tolerant and multifaceted cultural mentality that fights against the unification of thought.
\end{abstract}

Keywords: Utopian, Zhuangzi, Lin Yutang, Zhou Zuoren, Yan Lianke, Ge Fei

\section{Introduction}

Our era has come to the end of Utopia: Disillusionment about "the perfect society" or a utopian world community ruled by universal agreement has prevailed in the contemporary Chinese literary imagination. If at the end of the Qing dynasty, "modern Chinese literature was born with a call for utopia”, ${ }^{1}$ marked by Liang Qichao's novel The Future of New China (Xin Zhongguo weilaiji, 新中国未来记) in 1902, then after the whole century's strenuous effort to realize the revolutionary utopian dream resulted in disasters, contemporary Chinese writers became more fascinated with a dystopian imagination at the end of the twentieth century. For example, Yan Lianke’s Lenin's Kisses (Shouhuo, 受活) and Ge Fei’s Southlands Trilogy (Jiangnan sanbuqu, 江南三部曲, including Bygone Beauty (Renmian taohua, 人面桃花), Land in Dreamland (Shanhe rumeng, 山 河入梦), and Southern Spring Played Out (Chunjin jiangnan, 春尽江南)) are the representative dystopian novels, which target not only the deconstruction of the Communist Utopia but also the capitalist Utopia of postmodern China. In Jeffrey C. Kinkley’s words, “A dystopian novel of the Chinese stream is one that conveys inexorable and unbounded social-moral decline, particularly if that decline was engendered by a would-be utopian social scheme” (2015, p. 20). What has come along with the end of Utopia is the distrust of suprasocial justice, or a loss of faith in larger or higher sources of meaning, such as God, Heaven, or the Communist ideology. As a result, the yearning for the perfect society of justice and righteousness has been gradually transformed into the culture of indifference or nihilism in the post-Mao world. As Josep Ramoneda points out, "If totalitarianism is the annihilation of meaning, then the shape totalitarianism takes today is the culture of indifference" (2012, p. 119).

Facing such a dystopian mood, one might wonder what has gone wrong with the utopian impulse, the hope of overcoming the oppressive reality and constructing a perfect and just society. The Communist utopian dream of social harmony has become a hegemonic power to suppress individual expression and heterogenous ideas

LIU Jianmei, Ph.D., Associate Professor, Division of Humanities, Hong Kong University of Science and Technology.

${ }^{1}$ Please see David Der-wei Wang’s article "Panglossian Dream and Dark Consciousness: Modern Chinese Literature and Utopia" (a paper presented at the conference Utopia and Utopianism in the Contemporary Chinese Context: Texts, Ideas, Spaces, University of Hong Kong, March 20-21, 2015). 
and voices. Can we find an alternative spiritual resource in order to overcome the nihilism and indifference engendered by a dystopian mode? Was the Chinese utopian imagination based on Zhuangzi's spirit able to provide a different perspective from which to reconfigure a world free of suffering and beneficial to human fulfillment? Most utopian imaginations since the late Qing period, such as Kang Youwei's famous Book of Great Unity (Datongshu, 大同书), combine the Confucian utopian model found in Records of Rites with the Western evolutionary way of thinking. ${ }^{2}$ However, in those utopian ideals of a better future in which equality, unity, and harmony for all humanity are to be achieved, individuality and the rights of the individual have always been subjugated to collectivity and social reform. To grasp more precisely what may be at stake, this essay analyzes modern Chinese utopian imaginations inspired by Zhuangzi's spirit, which emphasizes individuality, freedom, and nature. On the surface, Zhuangzi's spirit may seem irrelevant to the utopian imagination, yet it perfectly complements what has been lacking in the modern utopian dream—individual spiritual liberation that resists any despotism of humanity and a more tolerant and multifaceted cultural mentality that fights against the unification of thought.

\section{Zhuangzi’s Spirit and Berlin's Negative Freedom}

The two central philosophical themes of Zhuangzi-absolute spiritual freedom as presented in the chapter “Free and Easy Wandering” (Xiaoyaoyou, 逍遥游) and the rejection of absolute and fixed views on right and wrong as seen in the chapter "On the Equality of Things" (Qiwulun, 齐物论) - have been constantly reinterpreted and appropriated by modern Chinese intellectuals in the twentieth century. ${ }^{3}$ The dilemma of the survival of these two important ideas can best testify to the inner struggle of modern Chinese intellectuals, who have to live under the collective utopian dream of Communist China. In the cultural environment in which Chinese writers were preoccupied with their “obsession with China” (C. T. Hsia’s term) (Hsia, 1999, p. 533-534), the pursuit of individual freedom as well as more tolerant and multilayered cultural identities have been relentlessly downplayed, suppressed, or criticized. However, Zhuangzi's advocacy of the absolute individual spirit can become a rich philosophical resource for aesthetic utopian and personal utopian imaginations, and his questioning of any fixed opinions concerning "right" and "wrong” can help us understand the all-encompassing Way (dao, 道) that denotes the spirit of tolerance of potentially conflicting and incommensurable values, offering a more human and liberal way of imagining the utopian world.

In his famous essay "Two Concepts of Liberty", Isaiah Berlin makes the distinction between "positive freedom", which insists on the wish to be one's own master, and "negative freedom", which encompasses "the area within which a man can act unobstructed by others" (2002, p. 169). Echoing Libertarians such as Locke and Mill in England and Constant and Tocqueville in France, Berlin holds that a certain minimum area of personal freedom cannot be violated. In other words, a substantial minimum area of negative freedom that cannot be trespassed upon by the state, the nation, or any other authorities is essential to a human being. "By being free in this sense I mean not being interfered with by others. The wider the area of non-interference the wider my freedom” (Berlin, 2002, p. 170). Instead of emphasizing the absence of interference, positive freedom means having control over one's life; but according to Berlin, it sometimes "may be inflated into some super-personal entity —a State, a class, a nation, or the march of history itself, regarded as a more 'real' subject

\footnotetext{
${ }^{2}$ See Zhang, Great Unity as a Social Vision.

3 Please see my book Zhuangzi and Modern Chinese Literature.
} 
of attributes than the empirical self” (Berlin, 2002, p. 181). By distinguishing negative and positive liberty, Berlin is targeting moral monism, which presupposes a single pattern, a blueprint, "a final solution" for a utopian society—a kind of ultimate premise of modern systems of authoritarianism (Berlin, 2002, p. 212). As he points out:

Pluralism, with the measure of "negative" liberty that it entails, seems to me a truer and more humane ideal than the goals of those who seek in the great disciplined, authoritarian structures the ideal of "positive" self-mastery by classes, or people, or the whole of mankind. It is truer, because it does, at least, recognize the fact that human goals are many, not all of them commensurable, and in perpetual rivalry with one another. (Berlin, 2002, p. 216)

Being suspicious of a single seamless system of value, Berlin urges us to affirm pluralism and eschew the unitary value that can be seen in utopianism and authoritarianism. Advocating pluralism, he in fact encourages us to embrace potentially conflicting and incommensurable values regardless of "higher" or "lower" goals, as well as their origins in the modern right or left wing.

Zhuangzi's idea of absolute spiritual freedom differs in important respects from the Western tradition of freedom. Berlin's differentiation between positive freedom and negative freedom is about rights within political and legal systems, whereas Zhuangzi is related to individual existence as well as an aesthetic spirit not confined in the context of rights. ${ }^{4}$ However, instead of viewing Berlin's concepts of negative freedom and Zhuangzi’s spiritual freedom as mutually exclusive, Liu Xiaogan in his book The Philosophy of Zhuangzi and Its Transformation not only has discovered the possibilities of conjunction and transformation between them but also has given Zhuangzi's concept of freedom a unique vantage point through which one is able to actively attain an infinite freedom in the world of consciousness, larger and more positive than Berlin's request for a minimal area of freedom. ${ }^{5}$ According to Liu, while the persistent and unremitting effort to survive in a harsh environment is by all means worth affirming, we nevertheless have no right to force everyone to be a fighter like Don Quixote, or to be a martyr and give up the freedom of choosing Zhuangzi's way of contentment on the spiritual level. Such a choice has its own legitimacy and should be understood or sympathized with, or at least not condemned, whether it is made under abnormal social conditions or during a peaceful period (Liu, 2010, p. 347-358).

In the field of artistic and literary creation, I also see certain affinities between Zhuangzi’s philosophy of “not being enslaved by things” (buweiwuyi, 不为物役) and Berlin's concept of negative freedom, a connection that implies Zhuangzi's significant applicability to a modern time in which individuals are coerced by a tyrannical doctrine in the name of one ultimate goal or ideal. Not being enslaved or controlled by things refers to a free and unfettered life, distant from politics, the state, social institutions, and human relationships that continually manipulate and hinder the individual. In its resistance to coercion and enslavement by outside factors, Zhuangzi's philosophy resonates with Berlin's negative freedom, which responds to some modern and contemporary problematics.

Zhuangzi’s relevance for the modern time lies exactly in the protection of individual liberty from external

\footnotetext{
${ }^{4}$ The difference between Berlin's two concepts of freedom and Zhuangzi’s freedom is discussed by Lin Gang: “Isaiah Berlin differentiated between positive freedom and negative freedom, but what he called negative freedom is undifferentiated from an ordinary discussion of rights within political and legal systems. But what is called freedom in Zhuangzi and Chan Buddhist tests is never discussed in the context of rights. It is not freedom in the sense of a political and legal system. Of course, freedom may relate to political and legal systems, but more importantly it points to existential issues of real individuals in life” (2014, p. 131).

${ }^{5}$ See Liu (2010), The Philosophy of Zhuangzi and Its Transformation, p. 347-358.
} 
restraint. In this sense, it is similar to negative freedom, which demands a space of noninterference by other people in which "one should be left to do or be what he is able to do or be" (Berlin, 2002, p. 169). In the modern world, Zhuangzi by and large not only represents an aesthetic spirit, a life philosophy, but also points to social and political dimensions of freedom, albeit on a symbolic level. It compels us to ponder if a man should have the right to independence, the right to roam, the right to noninterference by others, the right not to do something (yousuobuwei, 有所不为), the right to keep silent or live a reclusive life without participating in social reform or revolution-all crucial for artists and writers to maintain their personal voices and free literary and artistic creation.

In the context of modern Chinese literature, such a request for negative freedom, the right of noninterference or noncoercion by others, has usually been ignored or suppressed by modern authoritarianism, which depends on positive freedom-derived from the wish for self-mastery and self-determination but often historically twisted and channeled into a bigger cause, the emancipation of the nation. Therefore, whether to be a fighter, a savior of the nation, or just an individual with an authentic voice was constantly debated in the literary field of modern China. One of the most striking features of the history of modern Chinese literature has been the downplaying or even the invalidation of the right of roaming or negative freedom. Especially during the revolutionary years, Chinese writers were forced to become fighters to save either the people or the nation under political and social pressures, and as a consequence, their personal voices were turned into the mouthpiece of a political party or of a class or group.

One may argue that the freedom of an individual must be embedded in and is inseparable from freedom in a collective and political sense, as in Hu Shi's statement that "the big I" (dawo, 大我) and "the small I" (xiaowo, 小我) are always intertwined with each other (1919, p. 113-122). Whether in the revolutionary era or in a liberal democratic society, individual freedom has been closely tied to a politics that requires individuals to take on social responsibilities and serve their community, society, and nation. Such an argument can be understood as an extension of positive liberty, which according to Berlin is a "valid universal goal” (Berlin, 2002, p. 39). However,

the rhetoric of "positive" liberty, at least in its distorted form, is in far greater evidence, and continues to play its historical role (in both capitalist and anti-capitalist societies) as a cloak for despotism in the name of a wider freedom. (Berlin, 2002, p. 39)

For Berlin, positive liberty is divided between two selves: the "higher", "real”, or "ideal" self associated with reason and the "lower", "empirical", or "heteronomous" self associated with irrational desire and passion. ${ }^{6}$ In the name of the "true" or "real" self who aims to achieve a "higher" level of freedom, the empirical self, or people's actual desires and wishes, is constantly vulnerable to being suppressed by or forfeited to authoritarian ideologies.

As in the history of modern China, especially during the revolutionary era, what is at stake is not the lack of positive freedom but the vulnerability of negative freedom - an individual is not allowed to be negatively free to do as he pleases. For almost a century, Chinese writers have had the right to be a savior of or fighter for their nation, the spokesperson of the people, or the embodiment of social consciousness, but not the right to roam, to

\footnotetext{
${ }^{6}$ Berlin wrote: "Presently the two selves may be represented as divided by an ever larger gap; the real self may be conceived as something wider than the individual (as the term is normally understood), as a social 'whole' of which the individual is an element or aspect: a tribe, a race, a Church, a State, the great society of the living and the dead and the yet unborn” (2002, p. 179-180).
} 
be an outsider and a hermit, or to not fight for and participate in national salvation. As Gao Xingjian wrote,

During the years when Mao Zedong implemented total dictatorship even fleeing was not an option. The monasteries on faraway mountains that provided refuge for scholars in feudal times were totally ravaged and to write even in secret was to risk one's life. (2005, p. 15)

The moral monism on which revolutionary ideology was based invalidated the coexistence of positive freedom and negative freedom in the literary field, depriving Chinese writers of a choice between being a savior and enlightener of the people and being a normal and frail person who preferred to retreat into personal space. As a result, the modern utopian imagination that emphasizes changing and revolutionizing the world has greatly overwhelmed another kind of utopian imagination inspired by Zhuangzi's philosophy, which focuses more on the aesthetic spirit, individual freedom, the antialienation of the outer world, as well as a healthy relationship between human and nature.

By questioning any fixed views on "right and wrong”, Zhuangzi in the modern world not only symbolically echoes negative freedom but also reflects the problematic of a modern utopian imagination that lacks the spirit of tolerance of multiple values. In the chapter "On the Equality of Things", Zhuangzi was questioning the intellectual conflicts of his time, especially the different judgments of "rightness" and "wrongness" made by Confucianists and Mohists. ${ }^{7}$ For Zhuangzi, all such debates have ulterior motives behind them, prescribed by special circumstances and positions. In Benjamin Schwartz’s words,

It is not that the perspectives of Confucius or Mo-tzu may not have some truth when applied to certain situations, but their effort to encompass the infinite ocean of circumstances and perspectives with their own "rightness" and to find moral and intellectual "wrongness" everywhere is as much a manifestation of the self-assertive and isolating heart/mind as is the monomaniacal ambition of the tyrant. (1985, p. 231)

Indeed, instead of agreeing with any fixed opinions concerning "right" and "wrong”, Zhuangzi was advocating the all-encompassing Way that can contain and understand both of these opposites. The Way that Zhuangzi suggested implicitly signifies the spirit of tolerance, embracing conflicting and heterogeneous values - which has been largely ignored in the utopian imaginations in modern and contemporary Chinese literature.

\section{Zhou Zuoren's New Village_-Against Unification in Thought}

Apparently, Zhuangzi's concept of individual freedom had an extensive and profound influence on Zhou Zuoren, who overtly and firmly emphasized "ontological individualism in the worldly place" in his famous article “Human Literature (Rendewenxue, 人的文学)”. In Zhou’s own words, “the humanism that I talked about is starting from the individual. To talk about humanism and love all human beings, one must first gain the qualification of being a human, and having a human's position” (2002b, p. 11-12). By regarding each person’s rights as the precondition for humanism, Zhou Zuoren powerfully demonstrates that individualism is crucial to all aspects of human existence. Such an argument, prioritizing individualism as the starting point for social

\footnotetext{
${ }^{7}$ Zhuangzi is skeptical of the notion of fixed principles of "right and wrong”: “'This' is also 'that'; 'that' is also 'this'. 'This' implies a concept of right and wrong; 'that' also implies a concept of right and wrong. But is there really a 'this' and a 'that'? Or is there really no 'this' and no 'that'? Where 'this' and 'that' cease to be opposites, there lies the pivot of the Way. Only when the pivot is located in the center of the circle of things can we respond to their infinite transformations. The transformations of 'right' are infinite and so are the transformations of 'wrong'. Therefore, it is said that nothing is better for responding to them than lucidity” (Chuang, 1998, p. 15-16).
} 
reform, was perfectly epitomized by the "new village", a small utopian community initiated by Japanese novelist Mushakoji Saneatsu, who launched the journal New Village to advocate "New village-ism" (xincun zhuyi, 新村主义) in 1918. Infatuated with Mushakoji Saneatsu's utopian idea, Zhou Zuoren published an article entitled “New Village in Japan” (Riben de xincun, 日本的新村) in New Youth in 1919, praising the new village movement as a feasible ideal. In Zhou's own words,

The new village movement goes one step further, promoting a life of labor and collaboration. In one way, it has fulfilled the obligations toward human beings; in another way, it has completed personal duties to oneself. It eulogizes not only collaboration but also individuality; it develops not only the common spirit but also the spirit of freedom. It is indeed a practical and feasible ideal, and a blessing for normal people. (April 1919)

In July 1919, Zhou Zouren went to Japan to experience the real life in the "new village”, participating in the collaborative labor with other Japanese new village members for a few days and gaining enormous joy through such "a happy human life" that allowed him to transcend the rightness and wrongness in the mundane world. After he came back to China, he began to enthusiastically introduce such a utopian model to Chinese readers by publishing a series of articles and giving public lectures, which successfully aroused "a heat for new village” that even attracted Zhou Enlai, who became the prime minister of New China in 1949. In Zhou Zuoren's diary, he briefly recorded that Mao Zedong visited his home in Beijing in 1920 to consult him about the details of such a utopian model (Zhao, 2014, p. 12-30). However, although Mao Zedong's concept of the “People’s Commune” (renmin gongshe, 人名公社), which was put into practice all over China in the 1950s, absorbed some elements, such as collaborative labor and equality from the "new village," it largely abandoned the essence of the utopian model of the village, which is to respect individuals' rights and differences."The ideal new village, the reasonable society in the future, should on the one hand belong to mankind, and on the other hand emphasize the individual” (Zhao, 2014, p. 12-30). This kind of humanism truly represents the May Fourth spirit of enlightenment, but it was callously put into oblivion after the grand-scale "people's commune" was launched in New China. What Zhou Zuoren requested was analogous to "a certain minimum area of personal freedom” that Locke, Mill, and Berlin all believed are essential to human liberty. An ideal and harmonious New Village in which every individual can freely express his/her ideas is equivalent to Berlin's definition of negative freedom, which demands an area within which a man can act freely without being enslaved.

Zhou Zuoren's propagation of a "New Village" was even severely questioned and criticized by Hu Shi, who hierarchically subordinated a "small self" to the "greater self". ${ }^{8}$ In 1920, Hu Shi ruthlessly denounced the concept of a "New Village" because he saw a hidden affinity between such a utopian community and the traditional reclusive life of escapism, which fails to confront the backwardness of Chinese reality. In addition, it focuses too much on individualism, which in his mind would discourage youths from engaging in positive social reform. Immediately joining the debate, Zhou Zuoren again claims that "reforming society has to begin from reforming the individual” (2002f, p. 216), and the most valuable form of the New Village adopts peaceful means instead of the violent means of revolution.

In an important article entitled "The Ideal and Practice of the New Village" (Xincun de lixiang yu shiji, 新村的理想与实际) published in 1920, Zhou Zuoren meticulously imparts the utopian ideal of “New Village”

\footnotetext{
${ }^{8}$ Susan Daruvala has a detailed discussion about how Hu Shi's definition of individualism differs from that of Zhou Zuoren, who considers the individual as the starting point of social change. See Daruvala (2000), p. 51-52.
} 
by restating his definition of humanism with intense appeals for protecting and tolerating individual specialness:

The ideal life of a human in the New Village is in a world where sameness shows in a big way and differences show in a small way. As for the material life, it is the same; but the spiritual life can be free. In terms of mankind, everyone is the same; but in terms of the individual, everyone can be different and it is good to be different. Various countries, various places, various families, various persons - as long as everyone is aware that he is part of humanity, understands and helps others, and allows families and individuals from other countries to develop their specialties, then they should be welcome. (2002f, p. 216)

In his description of this utopian society, Zhou Zuoren highlights the foundation: people respecting individual spiritual freedom and tolerating different cultures and ideas. He especially emphasizes that the material life is the same, but the spiritual life can be free and different. In the ideal society of New Village, in which fame and money have lost their value, everyone has a peaceful and harmonious relationship with each other, enjoying the pure and genuine laboring life. The material life is as simple as possible, but the spiritual life is expected to be as rich as possible: not only promoting innovative artistic creation but also encouraging various religions.

More importantly, Zhuangzi's view of the uniformity of all things is loudly echoed in Zhou Zuoren's famous idea of tolerance (kuanrong, 宽容). ${ }^{9}$ Zhou Zuoren particularly abhors the kind of hypocritical “great harmony” (datong, 大同) based on despotic dictatorship:

If in the name of datong, someone suppresses special and different cultures and thoughts, then it is a new kind of despotism, which we should not have. Datong is completely different from unification (tongy统一). The unification of cultures and ideas is not only impossible but also unbearable. If there appears a kind of unified world in which everyone names each other with numbers, talks and acts the same, only knows what everyone else knows and doesn't know what everyone else doesn't know, then even if evolution can be expected, the monotonous and oppressive life itself is painful enough. (2002f, p. 216) $)^{10}$

Zhou Zuoren has envisaged the danger of imposing one way of life or one utopian pattern for the future, which depends at a deeper level on the moral monism that demands the sacrifice of the individual as well as the differences among individuals for the better future of society. This unification that presupposes a single and universal model that overrides the others can be seen in the Communist society, in which an individual's field of choice was narrowed and disciplined because of his/her propensity to find alternatives. Predicting the peril of such uniformity based on moral monism, Zhou Zuoren called for the spirit of tolerance that is capable of accommodating all the different and incommensurable ideas and identities—a spirit that admittedly has been emasculated in modern Chinese history. The scholar Ha Yingfei has given a nice summary of Zhou Zuoren’s thought:

Admitting difference; protecting the minority; tolerating dissidents; objecting to orthodoxy, dictatorship, and arbitrary acts; engaging in the construction of a modern rationality of multiple values; deconstructing the traditional unitary way of

\footnotetext{
${ }^{9}$ QIAN Mu thinks that Zhuangzi points out the limitations of human perception and the relativity of values: "Everything that has feeling and usefulness must have its own standard and Dao, therefore everything is equal and free”. FANG Dong-mei also thinks Zhuangzi's Qiwulun contains a real concept of equality: "I found a common basic position from here, which is that normal people, big bird, and philosopher, as well as everyone else, are equal”. Instead of emphasizing Zhuangzi’s insight about "freedom”, as LIZe-hou does in his History of Ancient Chinese Thought, both QIAN and FANG focus more on the idea of equality presented in Zhuangzi's Qiwulun, in which absolute universal moral values and standards are questioned. See QIAN (2002), p. 113; FANG (1993), p. 298.

${ }^{10}$ Zhou (2002f), Ideal and Practice of the New Village, in Arts and Life, in The Self-Selected Collection of Zhou Zuoren, p. 216.
} 
thinking and the psychology of idolization are the notable characteristics of Zhou Zuoren's thought. Or we should say, ZhouZuoren's idea of negating absolute authority is interconnected with Zhuangzi's relativism and agnosticism as well as Buddhism's theory of origin. (2008, p. 114-118)

Influenced by Zhuangzi’s “On the Equality of Things”, Zhou Zuoren is emphatic about tolerance and interrogates the idea of one universal truth in ethics and art because of our limited knowledge and perceptions. He especially appreciates his former mentor Zhang Taiyan's judgment that "what Zhuangzi is capable of are loyalty (zhong, 忠) and forgiveness (shu, 恕), and his so-called equating everything (qiwu, 齐物) brings up both loyalty and forgiveness” (Zhang, 2008, p. 451). In other words, the loyalty and forgiveness (zhongshu, 忠恕) that Zhang Taiyan describes are equivalent to tolerance, which transcends binary oppositions of positive and negative. In the afterword of The Theory and Interpretation of Equating All Things (Qiwulunshi, 齐物论释), Zhang Taiyan points out:

Equating all things is about equality, with which universal love and great harmony cannot compare. When we abandon both fame and image, the difference is automatically eliminated, and the pure and the polluted are both forgotten; therefore no truth is established. Only when things are not the same can sameness be reached. (2008, p. 412-451)

He reveals that Zhuangzi's concept of equality transcends the binary of the pure and the polluted, refusing to identify with a single and absolute truth; instead, it tolerates various big and small facts in the whole world, and such a spirit of tolerance is the quintessence of "On the Equality of Things". For scholars such as Cui Dahua, Zhang Taiyan's interpretation is "neither relativism on an experimental level, nor a compromise of opposed thoughts, but a deep philosophical observation that forms an understanding and tolerant attitude toward different thoughts" (Cui, 1992, p. 542). That is to say, by looking at the world from the perspective of the universe, Zhuangzi's “On the Equality of Things” contains a tolerant attitude and the real concept of equality, which includes multiple and different worlds without being obsessed with a single and absolute value judgment, and thus prevents arbitrariness of thought and one-sidedness.

Influenced by Zhang Taiyan's interpretation of Zhuangzi, Zhou Zuoren stated as early as the 1920s that "tolerance is the necessary condition for the development of the arts" (2002e, p. 8). He explained: "The reason for intolerance is that one insists on his own judgmental rights but doesn't acknowledge other people's; a literary person believes too much in his own school, regarding it as the only Dao" (Zhou, 2002e, p. 8). Since he firmly objects to the unification of thought, considering it the murder of art, he reiterates his criticism of intolerance in his essay “The Unification of Arts” (Wenyi de tongyi, 文艺的统一):

The above words, which are all accurate, are enough to prove that the unification of arts should not happen and is impossible, but a school of critics, in the name of society and mankind, has established an orthodox social literature, practicing a kind of unification invisibly. (Zhou, 2002c, p. 25)

Disagreeing that all kinds of literature should be united under the banner of "art for life's sake", he calls for allowing the existence of individual arts and literature that belong to "art for art's sake". In another article, “The Different Things in the Arts” (Wenyi de yiwu, 文艺的异物), he further expresses the idea of tolerating differences and even heresy:

The thought of different things in art is the same. I think everyone should have his own ideas, but at the same time he must have an encompassing heart and the spirit of understanding to appreciate all kinds of products, and only by doing so can he understand the real meaning of art. ... As a literary person, I think the reason literature is respectful is that its highest achievement is to ease all kinds of boundaries and distance. (Zhou, 2002d, p. 30) 
Indebted to Zhuangzi's spirit, about how to transcend right and wrong, limits and distances, Zhou Zuoren's concept of tolerance, which aims to embrace differences and respect others, questioning the absolute truth, not only strongly points to the literary field that lacked tolerance at the time but also foresees the hazard of modern authoritative thought that upholds monism in the long run. The writer Shu Wu comments:

As early as the 1920s, Zhou Zuoren objected to using the political movement to suppress individual thought. He predicted that even if this movement did not involve you, it would involve you in the future. No one has insurance. The “Cultural Revolution” that happened half a century later proved Zhou Zuoren’s words right. (2000, p. 133)

However, it was hard to be a modern Zhuangzi when Chinese intellectuals were expected to fulfill socially prescribed duties and obligations. It was also impossible to ignore right and wrong when reality was full of darkness and struggles. The case of Zhou Zuoren, who unfortunately degenerated into a Japanese collaborator, demonstrates that his dream of Zhuangzi was doomed to be dispelled under the historical condition of national crisis. In addition, his misery during the Cultural Revolution attests that there was no cultural space for his ideal of New Village that underscores individuality and tolerance in modern China, where Chinese intellectuals were caught in the collective dream of building a unified Communist society.

\section{Lin Yutang's The Unexpected Island—Following the Nature}

Lin Yutang's long novel The Unexpected Island, written in 1955, is a unique modern utopian novel that expresses his vision of an ideal world, drawn from both Western and Eastern cultures and philosophies. Different from the dream of "peach blossom spring" that only expresses the unitary traditional Chinese utopian imagination, this novel integrates Chinese Daoist culture and ancient Greek culture, creating an imagined community with universal human values as well as a deep criticism of the modern industrial society and material world, completely transgressing political and cultural boundaries. The opinions expressed in this novel targeting the problems of modern life remain as chillingly relevant today as at its first writing.

The Unexpected Island is set in 2004, when an American surveyor, Miss Eurydice, accidentally lands on an unknown and isolated island in the mid-Pacific and discovers that it is not only a European colony but also a modern "peach blossom land" that keeps itself insulated from the chaotic outside world. On this beautiful, quiet, and charming island, which is like a fairy-tale place, every inhabitant is happy, self-sufficient, highly educated, and living a free and laissez-faire life. Not knowing that World War III and World War IV have already happened and many countries are ruined, they just happily live in this isolated and heavenly world. Like Record of Peach Blossom Spring, in which a paradise is discovered through a fisherman's random adventure, The Unexpected Island reveals a poetic utopia through Miss Eurydice's adventure; the difference is that the fisherman can no longer go back to the Peach Blossom Land after he leaves, but Miss Eurydice eventually decides to stay on the island after careful observation and consideration.

As in other utopian novels, the setting of The Unexpected Island is a "nowhere" place, infused with Lin Yutang's personal imaginings and ideals of humanity. Through this other shore, Lin Yutang provides an alternative or resistant dimension to reflect the darkness and unfairness of reality, trying to rebuild confidence and hope for the future of mankind. Although the novel seems to escape from the world fraught with conflicts, suffering, and cruelty, it in fact contains very profound significance in criticizing modern reality. There are at least two time concepts in The Unexpected Island. First is the time of looking back, returning to the continuous cycle of nature; by doing so, the inhabitants of the island never need to pursue progress in technology or 
industry, only live in a beautiful natural environment with a carefree and content, leisurely lifestyle. Similar to the Daoist concept of "small country and few inhabitants", this time and place of stillness originally from the ancient tale of Peach Blossom Land is exactly opposite to the modern time of historical progress. Second, this time frame simultaneously points to the future, because the novel takes place in 2004; like George Orwell's 1984, it looks at the history of mankind from the perspective of the future, giving allegorical meaning to the reflection of modern society in which economic exploitation or social and political oppression has twisted human nature.

As one of the most important utopian novels in modern Chinese literary history that conspicuously criticizes modernity, which of course has a lot to do with the discursive context within which Lin Yutang was writing, The Unexpected Island conveys human understanding that is universal and timeless, common to all people in all places and at all times. Although a skeptical attitude toward modern urban culture is expressed in Shen Congwen's Border Town (Biancheng) and Fei Ming's Bridge (Qiao) through their poetic eulogies of pastoral life, no other modern Chinese writer is like Lin Yutang, who launches a comprehensive and strong attack on modern industrial civilization and the concept of progress by combining Western and Chinese ancient cultural resources. Lin Yutang is a distinctive cosmopolitan who pursues universal values and whose thought on cultural philosophy and world civilization transcends the boundaries of nations as well as history. His targets of criticism are modern men who are trapped in industrial and technological civilization and modern concepts that have been detrimental to people's welfare.Different from Lu Xun, whose criticism of national character only points to one race and one country, Lin Yutang addresses the whole of mankind's living and cultural conditions in which members of modern societies, both capitalist and communist, have lost individuality and personal freedom and are oppressed by the technologized, materialistic, and politicized status quo.

The spokesman for Lin Yutang in The Unexpected Island is Laos, a philosopher and the spiritual leader of this special island. He has diagnosed the mental disease that pervades the modern society: "Man is steadily going somewhere without knowing where he is going. Civilisation is gripped by a new disease, called men-no-pause” (Lin, 1955, p. 48). In opposing the nonstop progress of modern society dominated by machines, technology, and materialism, Laos leads some people to migrate to this isolated island and establish a "peach blossom land" in which a new type of civilization can be designed and a wholeness of humanity can be preserved. Laos says:

We don't repudiate progress - but are rather trying to stop in this mid-stream of progress and find our bearings, like standing on a rock in mid-river while the swift tide rushes past us. Call it a haven—if you like. A haven, a point to rest and think and live in peace. You will admit that thinking became impossible in the head-long progress of the twentieth century. Men were moving too fast. Vast changes, material discoveries affecting our lives, shortening of communications, obliteration of national frontiers through aviation-these changes happened so fast that men were dragged along. (Lin, 1955, p. 92-93)

This kind of speedy modernity that has an enervating influence on modern men causes the loss of poetry and sunshine, and the deterioration of human beings' original nature: individual authenticity, a naïve spontaneity that is often associated with childhood, and liberty unobstructed by modern authorities. Seeing that man has lost as much as he has gained ever since the industrial revolution, Laos says:

As more and more progress was made in the study of matter, less and less attention was given to man. Man's character had changed; his beliefs had changed; his relation to nature had changed; his individual role in society had changed. Spiritually, man was poorer. He was less himself. It would not be a bad idea to call a temporary moratorium on 
mechanical progress; what there was was good, but quite enough. (Lin, 1955, p. 49)

In The Unexpected Island, Lin Yutang raises extremely important philosophical questions: What exactly has man lost since the industrial revolution? What happened to philosophy as concerns the conduct of life? How can men search for their original self? How can men rediscover and restore their wholeness and authentic nature? How can men free themselves from the fetters of the outside world? How can men regain the lost poetry, sunshine, happiness, liberty, and individuality? All of those questions not only conduct a philosophical examination of human progress but also challenge the modern forces by reminding us of the philosophy of Zhuangzi and Zen Buddhism, which stresses returning to unpolluted true humanity.

The Unexpected Island-the modern "peach blossom land"-actually represents the ideal life in Lin Yutang's heart, natural and artistic, a "naturalization of humans", a return to the wholeness of human beings. Although Lin Yutang describes the island as a "colony", in which a high civilization takes control of the backward aboriginal civilization, if we only interpret this novel in terms of postcolonial theories, we ignore the true value and meaning behind the designation of this utopian island. Different from Tao Yuanming, who describes a pastoral life close to the Daoist ideal, Lin Yutang focuses more on a cultural and artistic life with high achievements from both Eastern and Western civilizations. Since the Unexpected Island is based on a combination of Zhuangzi's philosophy, Daoist culture, and ancient Greek culture, Lin Yutang aims to restore the cultural, artistic, and leisurely life rather than the aboriginal life or a plain rural life. For instance, in this hidden paradise, "Laos headed for the arts; they were very much on his mind. He was trying to cut life down to its essentials, and he could not cut good food, or a good bed, or violin music” (Lin, 1955, p. 51). Lin Yutang tries to present "the art of better living, of living well" (Lin, 1955, p. 188), or in other words, the enjoyment of life. Such a freer and happier mode of existence is in tune with Laozi’s and Zhuangzi's wuwei (nonaction), as opposed to the purpose and utilitarianism of the modern world. By highlighting the biological nature of human beings, as in both Daoism and Greek culture, Lin Yutang criticizes the fact that everything in the twentieth century has to be quasi-scientific. For example, Laos says:

Science wants to measure; it has to. Once you introduce the method of natural science into the humanities, however, you discard one by one that which you cannot measure-God, good and evil, sin and repentance, artistic creations, noble impulses. (Lin, 1955, p. 188)

Lin Yutang fights not the technology itself, but the prevailing technological and rational way of thinking, which propels efficiency and growth and accentuates purpose and goal, leaving no space for people to ponder the meaning of life or enjoy it.

Many modern Chinese writers are exceedingly fond of Greek culture. Zhou Zuoren enthusiastically translated ancient works and introduced Greek culture to Chinese readers. In his book History of European Literature, he summarizes the Greek spirit as the idea of paying attention to the present, the spirit of worshiping beauty, the principle of moderation. Regarding ancient Greek literature as a standard by which to measure literature of later generations, he basically describes the history of European literature as a cyclical process of the loss and the return of the Greek spirit. Zhou admires its emphasis on human nature, beauty, and the virtue of moderation that allows sense and sensibility to stay in a harmonious state. He thinks the Renaissance period was the return of ancient Greek culture (Zhou, 2002a, p. 55-57). For modern writers, ancient Greek culture is a frame of reference for natural humanity. For instance, Shen Congwen states in his preface to Border Town: 
Delicate, strong, balanced, although the shape is small, not weak - this is my ideal architecture. Inside the temple it is "humanity” that is being worshiped. (1992, p. 41)

Obviously for Shen Congwen, Greek culture represents beautiful and healthy humanity, a kind of free and ideal life state that has not been contaminated by modern civilization. In The Unexpected Island, Lin Yutang also expresses an ideal Greek spirit, pursuing not the perfect kingdom of divinity but the human kingdom that is closer to nature. Therefore, he portrays inhabitants of the Unexpected Island more as Greek men and women, who love the comfortable life and the universe and are interested in understanding the beauty of life itself. The assertions of surrendering oneself to ease and comfort, enjoying leisure, beauty, nature, poetry, and art, which echo Lin Yutang's early promotion of leisure discourse in China in the 1930s, are tinged with the Greek cultural spirit. In addition, just as the Greek gods are imperfect, the island inhabitants have a lot of human shortcomings: Crimes such as murder, rape, and domestic abuse have not been eliminated. However, it is precisely in this kind of imperfection that one can see the true human nature. The social and political structure of the island is also naturalized: There is no powerful and centralized government or strict and complicated laws. According to Laos, "the weaker the government and the more it was held in public contempt, the brighter burned the lamp of liberty, fraternity and equality for all” (Lin, 1955, p. 203). Basically governed by multiple communities in democratic form, this island allows all kinds of different identities to coexist harmoniously, such as Christian culture, aboriginal culture, Greek culture, Daoist culture, etc. This political structure offers a glimpse of Zhuangzi's spirit of open-mindedness and tolerance to understand multiple values, differences, and otherness.

For Lin Yutang, the common ground for Zhuangzi's philosophy and Greek culture is exactly the naturalization of humans. In the novel, taking the perspective of Zhuangzi, Laos says:

I want, first of all, a society where man can recover some of the individuality and independence he has lost. A simpler life. Why not? I want a grand, complete simplification of human life, to find out what man wants in this earthly life, that man may live in harmony with Nature. In the words of the Chinese philosopher, Chuangtse, that man may live out the peaceful tenor of his life, fulfilling his nature. "The universe gives me this form, this toil in manhood, this repose in old age, this rest in death”. To appreciate this universal harmony, the beauty of this cycle, and let our nature be fulfilled in it. And secondly, a society where the excellences of his being can be brought out, where man may develop himself along the lines of his excellences in ease and in freedom. (Lin, 1955, p. 116)

Only by returning to the natural human state can one obtain real freedom and find the complete self- this central theme of The Unexpected Island, not only inspired by Zhuangzi’s philosophy but also instigated by the Greek cultural spirit, clearly presents a new and healthy paradigm in which a plurality of values is amplified and a true meaning of individual liberty is protected. ${ }^{11}$ Indeed, the idealized portrayal of the Unexpected Island, which is construed as a search for an individual's inner freedom in accordance with nature, makes it an apt allegory for the aesthetic correction of the modern world that has gone astray.

In a general sense, Lin Yutang's The Unexpected Island is virtually the fictional version of his book The Importance of Living, with an additional Greek dimension. As Zhuangzi’s modern spokesman, Lin Yutang could hardly find a haven in which to escape attacks from both leftists and rightists in the Chinese literary field

\footnotetext{
${ }^{11}$ In the protagonist Laos's language, Lin Yutang reveals: “The whole psychology of his social philosophy may be stated in the cardinal Chuangtsean tenet that man must be free and able to pursue the even tenor of his span of life, and that his nature must be fulfilled. In terms of Greek Philosophy, man should be free to develop along the line of his excellence. That was the true meaning of freedom. All social happiness depends on it” (1955, p. 135).
} 
in the 1930s, subjugated by political concepts, ideologies, and -isms. Yet after he migrated to the West, he discovered that human beings are baffled by teleological modernity, and again he could barely escape from modern economic and technological domination. Becoming more and more pessimistic about the overly mechanistic and materialist tendencies in modern culture, he therefore designed an ideal cultural "Peach Blossom Spring” in his imagination and made it a peaceful and utopian home for his own heart, and for all mankind's heart and soul. As he reemphasizes, the reason he seeks such a utopia is not for the sake of saving the world—a notion that he bluntly defies as a modern lie—but for the sake of personal salvation, rediscovering the self that has been distorted by modern society.

\section{Conclusion}

As Jeffrey C. Kinkley argues, the literary dystopia in the postmodern China has been redirected from the future to the past, particularly represented by the genre of "new historical novels" (2015, p. 4-5). However, even among those novels that have shown disillusionment with the Communist utopian program during the revolutionary years and the capitalist utopia in the post-Mao era, Zhuangzi's spirit continues to inspire contemporary Chinese writers' literary imaginations.

Yan Lianke's Lenin's Kisses depicts an uncontaminated Shouhuo village that is analogous to Peach Blossom Spring, with a little twist: Only disabled people are allowed to live in and enjoy this paradise. The images of corporeal deficiency bear a conspicuous resemblance to a number of disabled people portrayed by Zhuangzi, who invests them with philosophical meanings. Zhuangzi believes those disabled people might suffer physical deformity but are capable of maintaining "virtue" in their heart. The Shouhuo villagers are similar to Shu in Zhuangzi, who benefits from his deformity by being exempt from military service and corvée labor. According to Robert Allinson, "Shu's virtues shine through his actions, or more precisely his lack of actions, not his words" (1989, p. 61). It is exactly through "nonaction" or making himself "useless" to the dominant group that Shu is able to preserve his life and avoid social entanglements. Likewise, benefiting from being marginalized and "useless", the Shouhuo villagers do not follow the political and social order and therefore have the luxury and right to enjoy their small, peaceful, and reclusive community. The significance of Yan's decision to connect the deficient with a utopia lies in the concept of "uselessness", a means to preserve individual nature and withdraw from a fallen world, but nonetheless a violation of normal standards of judgment. As David Harvey has said, "The particularity of the body cannot be understood independently of its embeddedness in social-ecological processes” (2000, p. 16). Indeed, the handicapped body is socially and culturally constructed and appears differently before and after joining the commune. When the handicapped are useless people living in the small community, they appear spontaneous, pure, natural, and happy; but after the Shouhuo villagers' special skills are discovered and they are turned into extremely "useful" money-making machines, they become deliberate, greedy, alienated, and unhappy, completely losing their true nature and humanity.

Ge Fei’s Southern Spring Played Out also conjures up Zhuangzi’s spirit as a counter discourse to fight against the capitalist utopia, in which everyone has degenerated into the slave of money as well as materialism. The protagonist Duanwu, who was a poet in the 1980s, became a self-marginalized and superfluous man amid the rapidly growing commercial society. As Zhuang Yinde argues, the image of Duanwu reminds us of not only “a superfluous man” inspired by Ivan Turgenev or Ivan Goncharov's fictional creation, but also Gunter Anders's "obsolete man", who is simultaneously "a utopian man", by which the author aims to criticize the 
material and technological society (Zhang, 2015). In addition, this obsolete poet is ostensibly inspired by the uselessness of Zhuangzi's philosophy, which provides an alternative way to criticize the speedy modernity and economic development that have aggressively enslaved and alienated the true nature of human beings (Zhang, 2015). As a lonely and obsolete poet amid the grand tide of money-chasing, Duanwu chooses to live a useless, marginal, and leisure life, which resembles Bai Juyi’s middle reclusive life (zhongyin, 中隐), which means neither “the big reclusive life” (dayin, 大隐) in the noisy and rumbustious city nor “the small reclusive life” (xiaoyin, 小隐) in a quiet and remote forest or mountains but rather to live between the two extremes, being a "useless" person who is free from social coercion (Bai, 1979, p. 490). Such an aesthetic person who withdraws from the frantic pursuit of economic utopia in postmodern China has maintained his integrity and genuine heart, returning to the interiority of an individual.

In his book The New Theory of Laozi and Zhuangzi (Lao-Zhuangxinlun, 老庄新论), the scholar Chen Guying aptly points out:

The way Zhuangzi talks about freedom is completely nonpolitical, but rather spiritual. Even on the level of politics, Zhuangzi holds the ideas that: first, one should operate according humans' natural nature; second, people should be bestowed freedom and subjectivity; third, the unification of thought is unacceptable, and instead, individual difference should be respected; fourth, one should be emancipated from the constraints of paradigms and -isms. (Chen, 1991, p. 265)

Since the late Qing period, the modern utopian imagination has usually been established for the purpose of reforming the national character and rebuilding new citizens. However, such a modern utopian dream has usually been grounded in utilitarianism, the disrespect of individuality, and ignorance of human's original nature. In the postmodern society, in which "the end of utopias" has triggered indifference and nihilism, Zhuangzi's spirit not only sheds light on modern utopian imaginations, which have been overshadowed by the monist way of thinking, but also becomes a source of hope that continues to illuminate our search for meanings.

\section{References}

Allinson, R. E. (1989). Chuang-Tzu for spiritual transformation: An analysis of the inner chapters. Albany: State University of New York Press.

BAI, J. Y. (1979). 白居易集 (The collection of Bai Juyi). Beijing: 中华书局.

Berlin, I. (2002). Liberty. H. Hardy, (Ed.). Oxford: Oxford University Press.

CHEN, G. Y. (1991). 老庄新辩 (The new theory of Lao-Zhuang). Hong Kong: 中华书局.

Chuang, T. (1998). Wandering on the way: Early Taoist takes and parables of Chuang Tzu (V. H. Mair, trans.). Honolulu: University of Hawaii Press.

CUI, D. H. (1992). 庄学研究 (The studies of Zhuangzi). Beijing: 人民出版社.

Daruvala, S. (2000). Zhou Zuoren and an alternative Chinese response to modernity. Cambridge, Mass.: Harvard University Asian Center.

FANG, D. M. (1993). 方东美集 (The collection of Fang Dongmei). K. J. HUANG \& X. L. ZHONG, (Eds.). Beijing: 群言出版 社.

GAO, X. J. (2005). 冷的文学 (Cold Literature). (G. C. F. Fong \& M. Lee, Trans.). Hong Kong: The Chinese University Press.

HA, Y. F. (2008). 论周作人的道家立场 (On Zhou Zuoren’s Daoist position). 贵州社会科学, 7, 114-118.

Harvey, D. (2000). Spaces of hope. Berkeley: University of California Press.

Hsia, C. T. (1999). A history of modern Chinese fiction (3rd ed.). Bloomington: Indiana University Press.

HU, S. (2003). 不朽一我的宗教 (Immortality-My religion). In 胡适全集 (The complete works of Hu Shi) (vol. 1, p. 659-668). Hefei: 安徽教育出版社.

Kinkley, J. C. (2015). Visions of dystopia in China's new historical novels. New York: Columbia University Press.

LIN, G. (2014). Toward an aesthetics of freedom. In M. Lackner and N. Chardonnens (Eds.), Freedom and fate in Gao Xingjian's writing (p. 121-137). Berlin/Boston: De Gruyter.

LIN, Y. T. (1955). The unexpected island. Melbourne: William Heinemann Ltd.

LIU, J. M. (2016). Zhuangzi and modern Chinese literature. New York: Oxford University Press. (in print) 
LIU, X. G. (2010). 庄子哲学及其演变 (The philosophy of Zhuangzi and its transformation). Beijing: 中国人民大学出版社.

QIAN, M. (2002). 老庄通辩 (The general distinction between Laozi and Zhuangzi). Beijing: 三聊书店.

Ramoneda, J. (2012). At the end of Utopia-Indifference. In P. Vieira and M. Marder (Eds.), Existential Utopia: New perspectives on Utopian thought (pp. 113-126). New York: Continuum.

Schwartz, B. (1985). The world of thought in ancient China. Cambridge, Mass.: The Belknap Press of Harvard University Press.

SHEN, C. W. (1992). 沈从文文集 (The collection of Shen Cong-wen). GuangZhou: 花城出版社.

SHU, W. (2000). 周作人的是非功过 (The merits and demerits of Zhou Zuoren). Shenyang: 辽宁出版社.

WANG, D. D. W. (2015). Panglossian dream and dark consciousness: Modern Chinese literature and Utopia. (Paper presented at the conference Utopia and Utopianism in the Contemporary Chinese Context: Texts, Ideas, Spaces, University of Hong Kong, March 20-21).

ZHANG, L. X. (2015). Great unity as a social vision. (Paper presented at the conference Utopia and Utopianism in the Contemporary Chinese Context: Texts, Ideas, Spaces, University of Hong Kong, March 20-21).

ZHANG, T. Y. (2008). 后序 (Afterword). In 齐物论释 (The theory and interpretation of equating all things). In D. J. HU (Ed.) 十家论庄 (Ten experts talking about Zhuangzi) (pp. 421-451). Shanghai: 上海人民出版社.

ZHANG, Y. D. (2015). The Utopia of the human: About Ge Fei's Jiangnan Trilogy. (Paper presented at the conference Utopia and Utopianism in the Contemporary Chinese Context: Texts, Ideas, Spaces, University of Hong Kong, March 20-21).

ZHAO, H. (2014).中国人的乌托邦之梦: 新村主义在中国的传播与发展 (The Chinese Utopian dream: The propagation and development of new village-ism in China). Taibei: 独立作家.

ZHOU, Z. R. (2002a). 欧洲文学史 (History of European Literature). Shijiazhuang: 河北教育出版社.

ZHOU, Z. R. (2002b). 人的文学 (Human Literature). In 艺术与生活 (Arts and life). In The self-selected collection of Zhou Zuoren (pp. 8-17). Shijiazhuang: 河北教育出版社.

ZHOU, Z. R. (2002c). 文艺的统一 (The unification of arts). In自己的园地 (My Own Garden). In The self-selected collection of Zhou Zuoren (pp. 24-26). Shijiazhuang: 河北教育出版社.

ZHOU, Z. R. (2002d). 文艺上的异物 (The different things in the arts). In 自己的园地 (My own garden). In The self-selected collection of Zhou Zuoren (pp. 27-30). Shijiazhuang: 河北教育出版社.

ZHOU, Z. R. (2002e). 艺术上的宽容 (The tolerance of arts). In 自己的园地 (My Own Garden). In The self-selected collection of Zhou Zuoren (pp. 8-10). Shijiazhuang: 河北教育出版社.

ZHOU, Z. R. (2002f). 新村的理想与实际 (The Ideal and Practice of the New Village). 艺术与生活 (Arts and life). In The self-selected collection of Zhou Zuoren (pp. 213-220). Shijiazhuang: 河北教育出版社.

ZHOU, Z. R. (April 1919). 日本的新村 (The New Village in Japan). 新青年. 